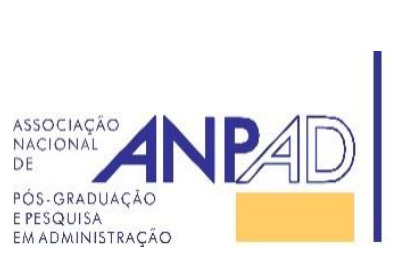

Available online at

http://www.anpad.org.br/bar

BAR, Rio de Janeiro, v. 14, n. 3, art. 3, e160087, 2017

http://dx.doi.org/10.1590/1807-7692bar2017160087

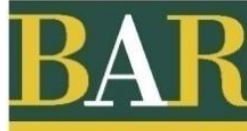

Brazilian

Administration

Review

\title{
Impacts of Interactive and Diagnostic Control System Use on the Innovation Process
}

Fábio Frezatti ${ }^{1}$ Diógenes de Souza Bido ${ }^{2}$ Ana Paula Capuano da $\mathrm{Cruz}^{3}$

Maria José C. Machado ${ }^{4}$

Faculdade de Economia, Administração e Contabilidade, Universidade de São Paulo ${ }^{1}$

Universidade Presbiteriana Mackenzie ${ }^{2}$

Universidade Federal do Rio Grande ${ }^{3}$

Universidade Metodista de Piracicaba ${ }^{4}$

Received 7 September 2016; received in revised form 29 June 2017 (this paper has been with the authors for two revisions); accepted 17 August 2017; first published online 21 September 2017. Editor's note. Márcia Martins Mendes De Luca served as Action Editor for this article. 


\begin{abstract}
This research explores the innovation process in organizations based on the Management Control System (MCS). We examined the link between the diagnostic and interactive uses of management control systems and their association with the intensity of the innovation process. Motivations for the research are: (a) enhance the potentiality of the model by including variables that are external to the organization, and (b) offer an empirical emergent country perspective on innovation. The study is quantitative and the data were collected by means of a survey questionnaire involving a sample of 121 Brazilian companies. The analysis was supported by structural equation modeling. The contributions are: (a) enhancement of the model by including the influences exerted by external stimuli on the intensity of innovation, (b) confirmation of the utility of the model in an emergent country, and (c) despite the controversial literature, highlighting the importance of the interactive use of the Management Control Systems process, by offering an empirical perspective on innovation control. A positive implication of the findings relates to the use of a broader and not exclusively internal model to increase its potentiality, reflecting the organizational reality by including the dynamism of external stimuli and the innovation control perspective.
\end{abstract}

Key words: innovation process; diagnostic control system; interactive control system, dynamic tension 


\section{Introduction}

The path to success in innovation involves a number of factors, and organizations must be constantly aware of the external environment and the search for new opportunities in order to develop a culture of innovation (Simons, 1995). When structured in this manner, organizations are able to plan processes that serve as the basis for systematically and collaboratively finding untapped opportunities, which is a feature that is considered as being fundamental to successful innovation (Teece, 2010).

Innovation has been studied by many researchers, such as Schumpeter (1997), Freeman (1995) and Damanpour (1991). Although much research has been developed, results regarding how the organizational structure inhibits or facilitates it are still not sufficient. For several reasons, the lack of success in the way that researchers have tried to examine the organizational structure, whether in terms of process or outcome, for example, has made it difficult to reconcile the results and improvements (Damanpour \& Gopalakrishnan, 1998).

Successful innovation, therefore, requires companies to plan innovation, and such planning must be supported by structured methods, tools, and frameworks that allow integration between multidisciplinary teams and areas of multiple specificities. This is a very important motivation for the research: to capture the relevance of the Management Control System (MCS) to the innovation process. However, it has been noted that the role of MCSs with respect to their contribution to organizational innovation has rarely been demonstrated and has even been ignored altogether (Arjaliès \& Mundy, 2013; Bisbe \& Otley, 2004). Although recognized, variables that are external to the organization are not included in the studies even though they produce internal turbulences that impact the organization. A broader model is thus required to capture these elements. There is an impact of not including the external variables, resulting from the fact that the models are extremely rigid and cannot capture changing needs, which is a very important part of reality. This is the first gap.

The second gap involves the lack of research beyond the Anglo-Saxon world. This is important in order to better address social activity, which is very far from regulated and normalized actions. Academics have been required to reassess and extend their theories in order to examine the strategic challenges businesses face in emerging economy contexts (Hoskisson, Eden, Lau, \& Wright, 2000; Meyer, Estrin, Bhaumik, \& Peng, 2009). It must be considered that there are different cultural contexts that reflect upon organizations (Cliff \& Jennings, 2005; Coviello \& Jones, 2004; Gupta, Levenburg, Moore, Motwani, \& Schawarz, 2011; Holt, Rutherford, \& Kurato, 2010) although research has indicated the benefit of MCSs to the innovation process (Bedford, 2015).

The approach of the traditional literature is to discuss diagnostic and interactive control systems (Ferreira \& Otley, 2009; Henri, 2006; Simons, 1995; Su, Baird, \& Schoch, 2015, Tessier \& Otley, 2012); however, the main focus of this analysis really involves the diagnostic and interactive uses of these control systems (Abernethy \& Brownell, 1999; Simons, 1991, 1994). This research approach provides an analysis that enables the same tool to be used in different ways and captures planning and monitoring actions for innovation projects. Consequently, this investigation leads to the following research question: what kind of association can the use of MCSs have with the intensity of the innovation process?

This article begins with an introduction that outlines the motivation behind the development of the study, the research question, and the difficult demands that certain organizations have faced when addressing innovation. Second section provides a literature review on the research topic, and third section presents the theoretical model explored in this study and the hypotheses developed. The methodological framework adopted is described in fourth section. Fifth section presents the results of the study, re-examining each of the tested hypotheses, and the last section presents the discussion and conclusions drawn from the study. 


\section{Literature Review}

For the development of this research, literature was reviewed and related to the following themes that compound the conceptual model: (a) external stimuli, (b) innovation strategy, (c) MCSs, (d) diagnostic use of control systems, (e) interactive use of control systems, (f) dynamic tension, and (g) innovation intensity.

\section{External stimuli}

The approach of Groot and Lukka (2000) is used to include elements that are external to the organization in the analysis because these elements can explain occurrences and dynamics within the management model. This is consistent with the proposal from Simons (1995), in that when recognizing external elements, the model is geared toward a perspective that is not static but is instead oriented towards change and the effect of external stimuli.

\section{Innovation strategy}

Innovation is a process that includes technical activity, design, development, and management that results in the commercialization of new (or improved) products or the first use of new (or improved) processes (Freeman, 1995).

Although some authors characterize the different innovation focuses by type (Gopalakrishnan \& Damanpour, 1994), they are generally characterized by strategy because strategy will indicate the way that innovation will be implemented and how the efforts will be allocated. Abernathy and Utterback (1978) studied innovation strategy in two groups: product and process. As for this study, the types researched were: product, process, technology, organization, and manner that product/service is offered.

\section{Management control system (MCS)}

Despite the existence of several different approaches to the concept of MCSs (Anthony, 1976; Anthony \& Govindarajan, 2008; Berry, Broadbent, \& Otley, 2005; Ferreira \& Otley, 2009; Malmi \& Brown, 2008; Simons, 1995), we based this study on Simons (1995). His definition states that MCSs: "are the formal, information-based routines and procedures managers use to maintain or alter patterns in organizational activities" (p. 5).

Diagnostic and interactive control systems are the parts of the mechanisms that provide support in the implementation of strategies or in adapting to competitive environments (Simons, 1995). The power of MCSs is not related to one of the specific levers but instead to the combination that produces the dynamic tension (Hofmann, Wald, \& Gleich, 2012; Simons, 1995). The intra-relationship between the uses of diagnostic and interactive systems is important and must be researched because of the need to understand the learning process (Ferreira \& Otley, 2009).

\section{Diagnostic use of control systems}

The diagnostic control system seeks to ensure that decisions align with the goals of the organization (Simons, 1995). Frequently, when authors refer to MCS, they typically only refer to the diagnostic information system. The diagnostic control system is the formal system of organizational information that monitors results and corrects deviations from expected performance standards (Chenhall, 2007). 


\section{Interactive use of control systems}

Simons (1995) reinforces the importance of the interactive system, which circumvents these problems and aims to provide answers to management elements that were not considered in the previously developed strategic planning process. Thus, the interactive control concerns the system that involves managers in the decisions of subordinates; this system's focus of attention is on the aspects of control that do not routinely appear in information systems (Abernethy \& Brownell, 1999). This provides the complementarity of both systems (Ferreira \& Otley, 2009; Hofmann et al., 2012).

\section{Dynamic tension}

Dynamic tension is an expression used by Simons (1995) to characterize antagonistic situations that must be defined (e.g., old vs. new, maintenance vs. change, freedom vs. restriction, and empowerment vs. accountability) and are, in a way, part of organizational life and management. Tensions are considered dynamic due to the continuous and varied strategic forces acting both internally and externally (Mundy, 2010). They are created by the ability to use diagnostic and interactive control systems, which must provide conditions for reconciliation of tensions between innovation and efficiency.

\section{Innovation intensity}

Intensity is another word to define what Damanpour and Gopalakrishnan (1998) treated as radicalness, and consists of a division between what is routine innovation and non-routine innovation and what produces a minor or major innovation. With regard to intensity, innovation may be incremental or radical (Gersick, 1991; Tushman \& Romanelli, 1985). Incremental innovation that encourages the status quo (Koberg, Detienne, \& Heppard, 2003) involves a lower level of impact and change than radical innovation (Un, Cuervo-Cazurra, \& Asakawa, 2010), and the process of reorientation produces fundamental changes in the activities of organizations, representing a clear departure from existing practices (Damanpour \& Gopalakrishnan, 1998).

\section{Theoretical Model and Hypotheses}

The theoretical model (Figure 1) takes into account the antecedents of managerial control (external stimuli and innovation strategies), the MCS itself (diagnostic and interactive control systems and dynamic tensions), and the innovation intensity. 


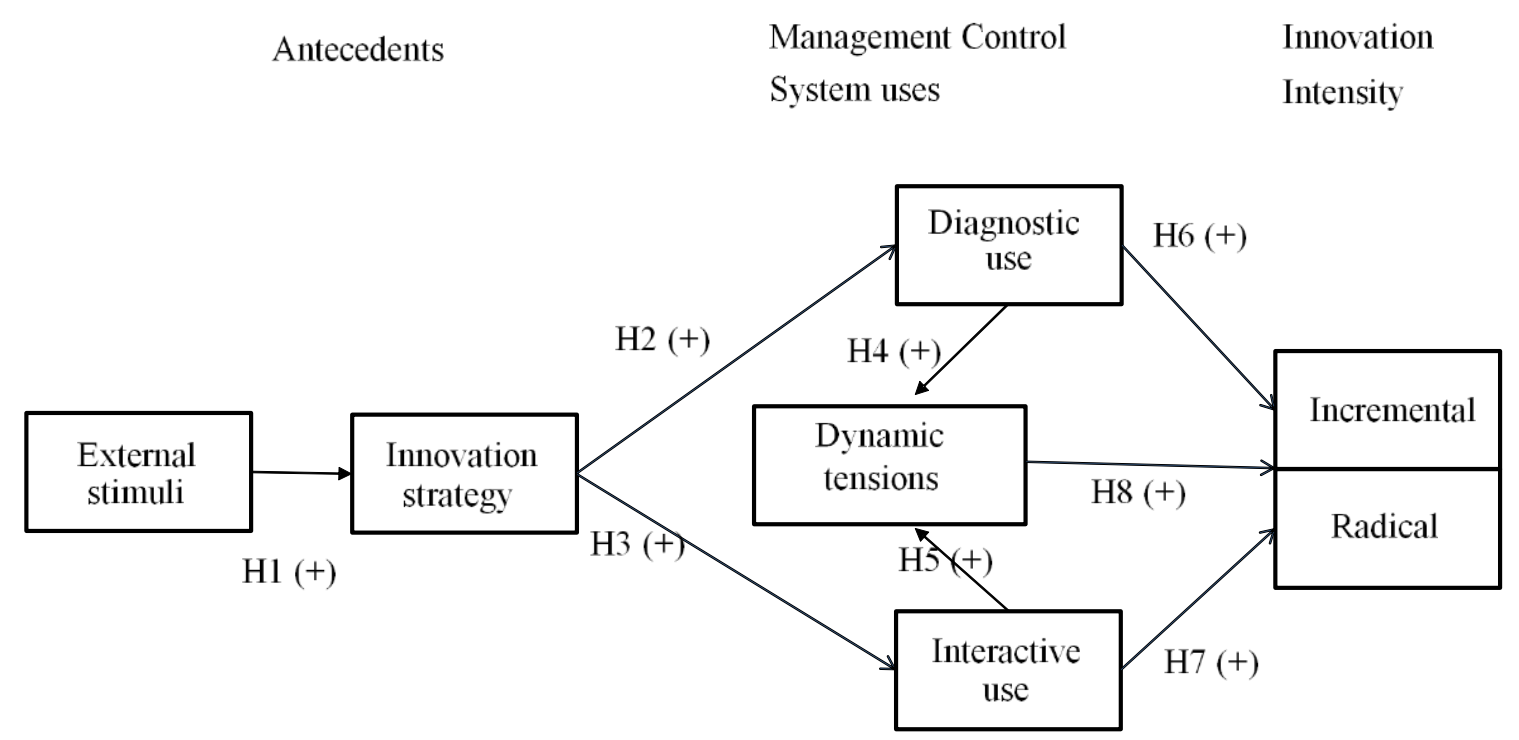

Figure 1. Theoretical Model of the Use of the MCSs as Innovation Mediators

\section{External stimuli and innovation strategy}

Organizations exist in a given environment and constantly interact with the external environment. Thus, in the hypothetical model in this study, it is assumed that there are antecedents to the use of control systems that correspond to external stimuli and innovation strategies. The organization formalizes the innovation strategies in its plans and the environment in which it exists is changing all the time. The relationship between external stimuli and innovation strategies $(e . g .$, the prioritization of actions focused on processes, products, and organization) is particularly relevant to understanding the organization's model as a whole (Coad \& Herbert, 2009; Kaplan \& Norton, 1996; Teece, 2010).

External stimuli can create pressure on innovation strategies in several ways, such as when the government changes regulations for a particular product, which could reduce the planned margin of a local producer. As a result, in its innovation strategy, the local producer will evaluate whether to continue the innovation process or postpone it. In negative circumstances organizations tend to reduce or postpone investment in innovation (Moll, 2015) and decisions require criteria for choosing projects to be protected.

Another example would be when the government in a particular country makes the trade rules more protectionist. In this case, a local organization could bring forward investment to increase the potential production of goods for local consumption. In the first example, the action could eliminate or reduce the innovation investment and in the second, the action moves the moment that the innovation is due.

In order to capture, understand, and assimilate external stimuli, an alignment is required with how the organization is accommodated in terms of internal thought processes, which depend on narrow or broad experiences that limit or expand the accommodation zone. Greater accommodation capacity will create knowledge capacity (Jarzabkowski, 2004) and the need for mechanisms to address new and more complex demands. In the case of government protectionism, previous experience of such changes creates knowledge for facing the challenges and avoiding undesirable alternatives and risks.

Additionally, the organization's capacity to track external forces depends on the power, capability, and knowledge of the relevant external structures (Coad \& Herbert, 2009). This means that a structured innovation strategy is required in order to understand, act and react in response to external stimuli. This leads to the formulation of the first hypothesis:

Hypothesis 1. External stimuli have a positive association with innovation strategies. 


\section{Innovation strategy and the diagnostic and interactive uses of MCS}

Despite the fact that the MCS should exist before an innovation project starts, as an antecedent, the innovation strategy, with projects focusing on products, processes, or organization, would affect use in terms of the frequency information is needed, the design, and details of the management mechanisms in order to support approvals and the monitoring process. The inclusion of innovation in the diagnostic and interactive control system is the ingredient that will contribute to shaping the internal environment of the organization (Bisbe \& Otley, 2004). Despite the fact that the literature tends to minimize or ignore the potential role of formal MCSs in influencing successful (product) innovation, there is evidence of a connection, at least in the case of low innovation organizations (Bisbe \& Otley, 2004).

Directing an innovation strategy for products, processes, technology, organization, and the manner that products/services are offered (Abernathy \& Utterback, 1978; Gopalakrishnan \& Damanpour, 1994) creates demands on the diagnostic and the interactive control system. Simons' (1995) framework challenges, in the way it applies to innovation, whether an interactive control system makes companies more inclined to develop and launch new products or whether it contributes to successfully enhancing the impact of the introduction of new products with planned performance (Bisbe \& Otley, 2004).

The diagnostic system involves two different moments of control: (a) ex-ante, when goals and objectives are defined and at some point are approved for the short, medium, or long term; within the strategic planning, balanced scorecard, capital budget, and budget and rolling forecast; we can get a common view of the organization, common vocabulary, and focus on the critical success factors; and (b) the second very important moment concerns the monitoring process when the organization follows up on goals, results, reviews key measures, and enables discussion on variations and provides inputs for adjustments when they are required.

Current literature (Bedford \& Malmi, 2015; Hoffmann, Mai, \& Smirnova, 2011; Su et al., 2015; Widener, 2007) suggests capturing the existence of diagnostic control use by means of specific questions about action and not by artifacts. In this research we captured the diagnostic use of control systems via the existence of the artifacts. This is especially important, as Simons (1995) considers that although the informal system is recognized, the main focus is the formal one, which exists when there are artifacts. This approach allows us to compare with the ex-ante and the monitoring of actual results that allows management to follow up on results and correct deviations from expected performance standards (Chenhall, 2007). Without focusing on the artifacts we cannot assure that the organization can handle the diagnostic use of the MCS.

It is expected that the more external stimuli occur, the more the interactive use of the control system will be adjusted and prepared for changes, capturing new informational needs for the management process. The literature does not distinguish, by types of innovation strategy or the different artifacts used. This leads to the formulation of the next hypotheses:

Hypothesis 2. Innovation strategies have a positive association with the diagnostic use of MCSs.

Hypothesis 3. Innovation strategies have a positive association with the interactive use of MCSs.

\section{Diagnostic and interactive uses of MCS and dynamic tensions}

Managerial control artifacts such as strategic planning, budgeting, the Balanced Scorecard, rolling forecasts, capital budgeting, and budgetary control are usually understood to be related to the diagnostic control system (Adler \& Chen, 2011). However, these artifacts can be used to stimulate the actions of the interactive system (Bisbe \& Otley, 2004; Henri, 2006).

The argument that MCSs cause an impact on dynamic tension is relevant (Henri, 2006; Hoffmann et al., 2011; Mundy, 2010; Widener, 2007) and the integration of them is impactful (Henri, 2006). Dynamic tension is affected by diagnostic and interactive uses of the MCS when it captures changes in 
plans and demands a response. The example of a tax increase for local producers, captured by the diagnostic use of the MCS, via a drop in margin, will stimulate discussions about alternatives and the interactive use of the mechanisms. It will drive discussions regarding maintaining an innovation plan or changing it, a very common and relevant example of dynamic tension. Therefore, based on this, the following hypotheses can be formulated:

Hypothesis 4. Diagnostic use of MCSs has a positive association with dynamic tension.

Hypothesis 5. Interactive use of MCSs has a positive association with dynamic tension.

\section{Diagnostic and interactive uses of MCS and innovation intensity}

Different and contradictory references address the diagnostic use of MCSs. One traditional approach considers that it could limit innovation and opportunities because its function is to ensure that plans are achieved (Henri, 2006; Jack \& Mundu, 2013; Mundy, 2010; Simons, 1995). This happens due to managers' tendency for coercive use (Ahrens \& Chapman, 2004), which reduces the potentiality of innovation in an organization, but this system's action should increase the predictability of achieving goals (Hoffmann et al., 2011).

Another approach, by Haustein, Luther and Schuster (2014), for example, suggests that management controls are useful if developed to address the needs of professionals. In addition (Bedford, 2015), there is a growing consensus that formal controls, when activated in an enabling, facilitative, and interactive fashion, increase the capacity of an organization to derive benefits from innovation.

Agbejule (2011) discussed the combined effect of the diagnostic and interactive uses of management control artifacts and found that less frequent use of diagnostic instruments and more frequent use of interactive tools generate a positive effect on performance. While the diagnostic control system is designed to improve efficiency and not to emphasize innovation (Davila, 2005), use of the system in tracking critical performance variables and monitoring and coordinating strategies is conducive to successful innovation. Cruz, Frezatti and Bido (2015) did not confirm the association between diagnostic system use and technological innovation, so this may denote that companies are facing difficulties in providing innovation indicators that are reliable and relevant to the organization as a whole.

The interactive control system should stimulate the demand and learning that make an organization's new or emerging strategies viable, unlike the diagnostic control system (Simons, 1995). Essentially, the interactive control system focuses on the entire organization, thus forcing the establishment of a dialogue between different parts of the company. It provides the basis for demanding the establishment of a specific agenda for debates of this nature, and thus motivates the search for information that circulates in channels other than those that normally attract the organization's attention for innovation projects (Simons, 1995).

In fact, there are some studies that did not conclude that the interactive control system contributes to innovation (Bisbe \& Otley, 2004) and this discussion can, over time, provide different reactions and conclusions (Bisbe \& Malagueño, 2009). Cruz et al. (2015) show that the use of the Interactive Control System positively is associated with technological innovation, since it plays a relevant role in the development of actions that allow the articulation of current and emerging strategies in the innovation process.

Radical and incremental innovation are different intensity perspectives. Bedford (2015) separated innovation intensity in accordance with a similar perspective, which is exploitation and exploration. Exploitation, in the incremental sense, drives "refinement, choice, production, efficiency, selection, implementation, execution", while exploration, in the radical innovation sense, is indicative of "search, variation, risk taking, experimentation, play, flexibility, discovery, innovation" (March, 1991 as cited in Bedford, 2015, p. 13). As a result of the innovation process, management requires different mechanisms 
in order to address different risks, terms, and magnitudes of investments, thus supporting different MCS designs.

Radical innovation is more frequently adopted in cases of new technology and a strong long term technology strategy (Ettlie, Bridges, \& O'Keefe, 1984) and it is more affected by bureaucratic control and diagnostic use than incremental innovation (Damanpour \& Gopalakrishnan, 1998). Incremental innovation can be found in several different perspectives, such as in an organization's MCS, the allocation of resources, technology, and structure of change rather than one type of change. Radical innovation produces technological advances so that no increase in scale, efficiency, or design could make older technology as competitive (Koberg et al., 2003), but it is probably more risky and consequently more impacted by diagnostic use.

Incremental innovation creates an environment of innovation due to the possibility of several different areas of an organization being part of the innovation effort. A culture of innovation is an important element to be stimulated by the management control structure and a combination of mechanisms can impact this (Chapman, 1997; Chenhall \& Morris, 1995).

These benefits lead to the formulation of the following hypotheses:

Hypothesis 6. Use of the diagnostic control system positively affects the intensity of innovation.

Hypothesis 7. Use of the interactive control system positively affects the intensity of innovation.

\section{Dynamic tensions and innovation intensity}

The benefit of dynamic tensions is that they produce competitive advantages and organizational capabilities (Henri, 2006; Mundy, 2010; Widener, 2007). Finding the correct balance between control and freedom of action is not easy when optimizing available resources and tools (Mundy, 2010). In summary, dynamic tensions could involve three different facets of an organization: (a) the dynamics of creating value, such as unlimited opportunities versus limited attention (Henri, 2006; Simons, 1995), or flexibility versus control (Davila \& Wouters, 2005; Simons, 1995), (b) the dynamics of strategy making, such as intended strategy versus emergent strategy (Henri, 2006; Simons, 1995), or growth versus risk (Porter, 1989; Sutton, 1998), or long-term versus short-term (Sitkin, 1996), and (c) the dynamics of human behavior, such as self-interest versus the desire to contribute (Henri, 2006), or competition versus cooperation (Etherington \& Tjosvold, 1998).

Radical and incremental innovation are treated differently in organizations. Although both are relevant, radical innovation is the one that can leverage sustainability. Here the organization actually captures, understands and absorbs changes in external stimuli and processes adjustments or maintains trends. Incremental innovation, with low risk, could be less affected by dynamic tension due to a change in regulatory issues than radical innovation. Therefore, based on these arguments, the following hypothesis can be formulated:

Hypothesis 8. Dynamic tensions positively affect innovation intensity.

\section{Methodology}

This section describes the methodological procedures used in the development of this study, particularly those that help in understanding its operationalization. The following information is provided: (a) the data collection tool, (b) the data collection process itself, and (c) the resources used to process and analyze the data. 


\section{Data collection tool}

This research was conducted using a questionnaire consisting of assertions, divided into blocks, seeking to map information concerning the following: (a) the external stimuli that affect the innovation process, (b) the innovation strategies used by the organizations studied, (c) the diagnostic use, (d) the interactive use, (e) the dynamic tensions found in these organizations, and (f) the intensity of innovation (incremental versus radical).

The definitions of the questionnaire, created by the authors, are:

\section{External stimuli}

The issues contained in the external stimuli were defined by Groot and Lukka (2000). The specific assertions were extracted from the following literature: the dynamics of international competition (Gupta \& Govindarajan, 2001; Hunt \& Duhan, 2002), governmental regulation and deregulation (Carter, Clegg, \& Kornberger, 2010; Haustein, Luther, \& Schuster, 2014), customer increases and demands (Haustein et al., 2014; Hunt \& Duhan, 2002), restrictions on the availability of scarce resources (Haustein et al., 2014; Zimmerman, 2011), and competitor advances that threaten current and future products (Hunt \& Duhan, 2002). The Likert scale defined by the authors is: 5 (strongly agree), 4 (partially agree), 3 (neither agree nor disagree), 2 (partially disagree), 1 (strongly disagree), 0 (do not know).

\section{Dynamic tensions}

We extracted from Simons (1995) and Henri (2006) the elements for the specific assertions about: unlimited opportunities, current strategies, emerging strategies, managing self-interest, and desire to contribute to the organization. The Likert scale defined by the authors is: 5 (strongly agree), 4 (partially agree), 3 (neither agree nor disagree), 2 (partially disagree), 1 (strongly disagree), 0 (do not know).

\section{Innovation strategy}

Abernathy and Utterback (1978); Daft and Macintosh (1978); Damanpour and Evan (1984); Gopalakrishnan and Damanpour (1994); Rogers (1995) are the references for the specific assertions about: innovation strategies involving processes, products, technologies, the organization, and the manner in which products and services are marketed/offered. The Likert scale defined by the authors is: 5 (strongly agree), 4 (partially agree), 3 (neither agree nor disagree), 2 (partially disagree), 1 (strongly disagree), 0 (do not know).

\section{Diagnostic use of MCS}

Simons (1995) is the source of the mechanisms of the diagnostic use of MCS. They are: goals and objectives systems, business plans, profit plans and budgets, brand revenue/market share monitoring systems, human resource plans, project monitoring systems, and standard cost accounting systems. Consequently, the inspiration for the assertions comes from the same source. The scale defined by the authors is: 4 (exists and is used to measure and monitor the effect of innovation), 3 (exists and is used in a general way, not to monitor innovation), 2 (exists but is not really used by management), 1 (does not exist in the organization), 0 (do not know).

\section{Interactive use of MCS}

Simons (1995) and Widener (2007) are the sources of the elements of the interactive use of MCS and corresponding assertions. They are: information generated addressed to highest levels of management, frequent and regular attention from operating managers at all levels of the organization, data is interpreted and discussed face-to-face in meetings of superiors, managers and peers and the system is catalytic for continual challenge and actions plans. The scale defined by the authors is: 4 (exists and is used to measure and monitor the effect of innovation), 3 (exists and is used in a general way, not to monitor innovation), 2 (exists but is not really used by management), 1 (does not exist in the organization), 0 (do not know). 


\section{Innovation intensity}

The radical and incremental approaches are the elements extracted from Ettlie, Bridges and O'Keefe (1984). The Likert scale defined by the authors is: 5 (strongly agree), 4 (partially agree), 3 (neither agree nor disagree), 2 (partially disagree), 1 (strongly disagree), 0 (do not know).

In order to minimize common method bias (CMB), we used the procedural approach (Podsakoff, MacKenzie, Lee, \& Podsakoff, 2003) maintaining confidentiality and protecting respondent anonymity. Additionally, to assess CMB we used Harman's single-factor test (Chang, Witteloostuijn, \& Eden, 2010). The exploratory factor analysis of all 26 items (principal components extraction) resulted in seven components (63\% of total variance extracted), and the first unrotated component extracted just $23 \%$ of the variance, which means that CMB is not a concern in our model.

\section{Data collection process}

To delimit the population, the studied companies were extracted from a list provided to the authors by a Brazilian publication, known as Melhores \& Maiores (Revista Melhores \& Maiores, personal communication, February 2011). None information was extracted from that publication. We pointed the references out as the annual rotation of companies in the edition is high. Of the 1,825 organizations listed in this publication (the target population), a sample of 121 companies was obtained and defined for convenience. Data collection was conducted via email between June and August 2011 with technological support from the Formsite system.

The companies were contacted by telephone to confirm receipt of the message, present the research to respondents, and request their cooperation in completing the questionnaire (Appendix). The data showed that $75 \%$ of respondents had been in their company for over five years, and $71 \%$ had been in their current position for over five years, with $63 \%$ holding the office of director or superintendent and $24 \%$ holding that of manager.

\section{Data analysis}

In addition to univariate descriptive analysis, structural equation modeling (SEM) was used with estimation by Partial Least Squares Path Modeling (PLS-PM), which was considered the most appropriate method for this research because of the non-normality of the data, the small sample made available for SEM estimation based on covariance, and the exploratory nature of the research (Hair, Hult, Ringle, \& Sarstedt, 2014, Henseler, Ringle, \& Sinkovics, 2009; Ringle, Sarstedt, \& Straub, 2012).

\section{Results}

\section{Demographic data}

The 121 companies analyzed in this study operate in 21 distinct sectors. Although there was some balance between the various sectors, most of the sample came from the service (18), chemical and petrochemical (10), and energy industries (10). There was a concentration of revenues in the range of $\$ 101-500$ million (62), and most of the organizations (111) were not listed companies.

\section{Assessment of the measurement model}

Before testing the hypotheses, it was necessary to ascertain whether the measurement of constructs was adequate. Convergent validity, discriminant validity, and reliability were tested for this purpose. Regarding convergent validity, it could be observed that all indicators showed significant factor 
loadings $(\mathrm{p}<0.01)$ and the average variance extracted from the seven latent variables was greater than $47 \%$ (Table 1).

Table 1

\section{Matrix of Correlations between Latent Variables}

\begin{tabular}{|c|c|c|c|c|c|c|c|}
\hline Latent variables & 1 & 2 & 3 & 4 & 5 & 6 & 7 \\
\hline 1. External stimuli & 0.724 & & & & & & \\
\hline 2. Innovation strategies & 0.384 & 0.687 & & & & & \\
\hline 3. Incremental & 0.171 & 0.285 & 1.000 & & & & \\
\hline 4. Radical & 0.097 & 0.336 & 0.153 & 1.000 & & & \\
\hline 5. Dynamic Tension & 0.219 & 0.303 & 0.080 & 0.126 & 0.711 & & \\
\hline 6. Diagnostic use of MCS & 0.270 & 0.240 & 0.153 & 0.249 & 0.276 & 0.721 & \\
\hline 7. Interactive use of MCS & 0.320 & 0.336 & 0.177 & 0.264 & 0.474 & 0.314 & 0.795 \\
\hline $\begin{array}{l}\text { Average Variance Extracted } \\
\text { (AVE) }\end{array}$ & 0.524 & 0.471 & 1.000 & 1.000 & 0.505 & 0.519 & 0.632 \\
\hline Composite Reliability & 0.766 & 0.813 & 1.000 & 1.000 & 0.801 & 0.881 & 0.895 \\
\hline
\end{tabular}

Note. 1: Correlations greater than $|0.180|$ are significant at $5 \%$ and greater than $|0.230|$ are significant at $1 \%$. 2: On the diagonal the square root of the average variance extracted is shown in bold.

It is noteworthy that values above $50 \%$ have been recommended for average variance extracted (Henseler et al., 2009; Ringle et al., 2012), and the values could be increased by eliminating indicators with smaller factor loadings in this case. However, because eliminating them would undermine the content validity and replicability of the study (Devellis, 2003, Little, Lindenberger, \& Nesselroade, 1999), the decision was made to keep these indicators.

Discriminant validity was evaluated at the indicator level, and it could be observed that all had greater factor loadings in their respective latent variable than in any other; it was also evaluated at the latent variable level, as can be observed in Table 1, where the square root of the average variance extracted was greater than the correlations between latent variables (Henseler et al., 2009; Ringle et al., 2012). Therefore, discriminant validity is adequate.

The composite reliability of all latent variables was higher than 0.7 , a value that is considered adequate by Hair, Black, Babin and Anderson (2010).

\section{Evaluation of the structural model}

The evaluation of the structural model took into account the structural coefficient results, which were, in turn, compared with the correlations when the possible occurrence of non-significant results was suspected because of multicollinearity (Cohen, Cohen, West, \& Aiken, 2003). Table 2 contains structural relations statistics. 
Table 2

Matrix of Path Coefficients

\begin{tabular}{|c|c|c|c|c|c|c|}
\hline Structural relations & $\mathbf{R}^{2}$ adj. & $\mathbf{f}^{2}$ & $\begin{array}{l}\text { path } \\
\text { coeff }\end{array}$ & $\begin{array}{c}\mathbf{P} \\
\text { values }\end{array}$ & $\begin{array}{l}\text { Hypo- } \\
\text { theses }\end{array}$ & Supported \\
\hline External stimuli -> Innovation strategies & 0.140 & 0.173 & 0.384 & 0.000 & $\mathrm{H}_{1}(+)$ & yes \\
\hline Innovation strategies -> Diagnostic use & 0.050 & 0.061 & 0.240 & 0.021 & $\mathrm{H}_{2}(+)$ & yes \\
\hline Innovation strategies -> Interactive use & 0.105 & 0.127 & 0.336 & 0.000 & $\mathrm{H}_{3}(+)$ & yes \\
\hline Diagnostic use of MCS -> Dynamic tension & 0.230 & 0.023 & 0.140 & 0.162 & $\mathrm{H}_{4}(+)$ & no \\
\hline Interactive use of MCS $->$ Dynamic tension & & 0.220 & 0.430 & 0.000 & $\mathrm{H}_{5}(+)$ & yes \\
\hline Diagnostic use of MCS -> Incremental & 0.018 & 0.011 & 0.111 & 0.212 & $\mathrm{H}_{6} \mathrm{a}(+)$ & no \\
\hline Interactive use of MCS -> Incremental & & 0.018 & 0.153 & 0.067 & $\mathrm{H}_{7} \mathrm{a}(+)$ & yes \\
\hline Dynamic tension -> Incremental & & 0.000 & -0.023 & 0.818 & $\mathrm{H}_{8} \mathrm{a}(+)$ & no \\
\hline Diagnostic use of MCS -> Radical & 0.078 & 0.035 & 0.189 & 0.068 & $\mathrm{H}_{6} \mathrm{~b}(+)$ & yes \\
\hline Interactive use of MCS -> Radical & & 0.039 & 0.219 & 0.019 & $\mathrm{H}_{7} \mathrm{~b}(+)$ & yes \\
\hline Dynamic tension $->$ Radical & & 0.001 & -0.030 & 0.770 & $\mathrm{H}_{8} \mathrm{~b}(+)$ & no \\
\hline
\end{tabular}

Note. Effect size ( $\mathrm{f}^{2}$ ) classification (Cohen, J. (1988). Statistical power analysis for the behavioral sciences (2nd ed.). (pp. 413414). New York: Psychology Press): 0.02 = small, $0.15=$ medium, $0.35=$ large. All VIF $<1.4$

\section{Hypotheses analysis}

This subsection presents the analysis of the hypotheses.

Hypothesis 1. External stimuli have a positive association with innovation strategies.

The hypothesis was supported (medium effect, $\mathrm{f}^{2}=0.173$ ). Although there is previous literature referring to external elements impacting organizations (Groot \& Lukka, 2000; Kaplan \& Norton, 1996; Simons, 1995), a model that includes this is not available.

In general, the organizations have low levels of control over these elements, which had a major effect on the organizations' survival due to them demanding dynamic and adaptable management. This finding indicates that relevant changes in these variables require alterations to an organization's direction in terms of innovations in processes, products, in the organization itself, or the manner in which products and/or services are delivered. In situations in which organizations do not capture external changes, innovation strategies may be obsolete or too shy with regards to taking advantage of opportunities.

Hypothesis 2. Innovation strategies have a positive association with the diagnostic use of MCSs.

Hypothesis 2 was supported (small to medium effect, $\mathrm{f}^{2}=0.061$ ). The connection with innovation strategy in terms of products, processes, or the organization is relevant, since the opposite is expected from the diagnostic use, which is a barrier to the innovation process. Despite the diagnostic use of the management information system being designed to ensure that what was planned is executed (Henri, 2006), which could be understood as a restriction for innovation, it is part of the process and might be used in planning and monitoring cycles. The combination of moments of ex-ante control and monitoring 
provides the conclusions for managers to address the innovation process by keeping the strategic orientation that inspirited the project but adjusting it when required. In order to achieve this, the design must be updated. Depending on the complexity of the project, in terms of required investments and risk (Germain, 1996) or the degree of newness of the innovation, the existence of the diagnostic use is the element that would make innovation possible and also ensure risk and performance control (Ettlie et al., 1984).

This finding maintains the importance of innovation but adds an element of control to the process, provided by the artifacts of the diagnostic Management Control System (MCS). It means that if an innovation project is approved there is a need to implement it in accordance with what was planned and approved in order to achieve the desired performance that was committed to.

Hypothesis 3. Innovation strategies have a positive association with the interactive use of MCSs.

As for Hypothesis 3, this was supported by the field research (medium effect, $\mathrm{f}^{2}=0.127$ ). The innovation strategy drives the interactive use of MCSs, via new possibilities in products, processes, and the organization. Many areas and people in an organization participate in different types of innovation. Identifying the types will provide alerts for management and ensure a place in their agenda. Although the same artifacts will probably be used, such as budget, forecast, and budget control, the response leads to changes and the rule of the mechanisms is to identify change drivers and anticipate their consequences. Innovation strategies had a positive association with interactive control use, which is consistent with the literature (Simons, 1995).

The interactive use approach more than simply identifies opportunities, but also revitalizes the planning process by including elements that were not considered in previous strategic planning and budgeting and creates conditions for new planning cycles to forecast. The more alternatives and greater complexity management faces, the more interactive use of the MCS is required and, depending on the information, agents might change their decisions (Chong, 1996).

Hypothesis 4. Diagnostic use of MCSs has a positive association with dynamic tension.

Hypothesis 4 was not supported. In this case (Mundy, 2010), diagnostic use should reconcile tensions between innovation and efficiency. Having on hand information regarding planned and actual results captures impacts and enables the discussion and reflection that is expected from the dynamic tension. For example, when the budget control provides information that an innovation project's expenses are higher than expected, this demands actions from the interactive side and decisions about what management should do. Alternatives such as accepting the variation and adjusting the margin, reducing other expenses, bringing forward the product's launch, selling the brand, or changing the product could be offered.

One possible reason the hypothesis was not supported could be that the dynamic tension variables that are addressed by the MCS were not sensitive for the sample.

Hypothesis 5. Interactive use of MCSs has a positive association with dynamic tension.

Hypothesis 5 was supported (medium to large effect, $\mathrm{f}^{2}=0.220$ ), in accordance with the previous literature (Henri, 2006; Simons, 1995). Dynamic tensions, therefore, have a significant effect on the use of interactive control to follow up on and monitor opportunities that can be identified, for example in the context of unlimited opportunities versus limited attention (Henri, 2006) or flexibility versus control (Davila \& Wouters, 2005). In other words, the interactive use is the tool that can instigate identifying alternatives for the external stimuli that the organization faces. It requires management to use the information from an interactive perspective, questioning or motivating people in the organization. More dynamic tensions are perceived with greater use of the interactive control system.

Hypothesis 6. The diagnostic use of MCSs positively affects the intensity of innovation. 
In the combination of both, radical and incremental innovations, this hypothesis was not supported. Considering the effect of diagnostic use on radical innovation in isolation, the hypothesis was supported (small effect, $\mathrm{f}^{2}=0.035$ ). Kober, $\mathrm{Ng}$ and Paul (2007) found out that meetings to discuss budgets, a typical diagnostic control system tool, are associated with organizational strategy. Although such artifacts are not intended for use in discussing strategy, their use inspires reflection on that strategy. Similarly, Naranjo-Gil and Hartmann (2007) examined the subject of artifacts moderating the relationship between strategy and innovation. Thus, MCSs play a critical role in creating pressure on organizations to adapt and innovate.

Although the hypothesis was motivated by the literature suggesting that the use of the diagnostic system is less frequent (Agbejule, 2011), most of the authors indicated it as a restriction (Davila, 2005; Simons, 1995). Arjaliès and Péan (2009) and Malagueño and Bisbe (2010) obtained similar results. A possible reason for the hypothesis not being supported is that most of the sample may have projects that are in the range of planned performance, which reduces the restrictive approach of the diagnostic use but instead enables projects already underway to continue, in accordance with some acceptable level of performance.

Hypothesis 7. The interactive use of MCSs positively affects the intensity of innovation.

This hypothesis was supported (small effects). The findings support the approach of Simons (1995) and are inconsistent with the findings of Bisbe and Otley (2004), who did not obtain evidence that this occurs. In one sense, the flexibility provided by the interactive system has an effect on the intensity of both radical and incremental innovation. In more objective terms, an organization that has both levels of innovation (incremental and radical), regardless of its industry sector and type of business, is more connected to the interactive control system with radical than with incremental innovation.

From the perspective of this paper, because we captured the diagnostic use by identifying the artifacts that enable it, we can see that by having such mechanisms the interactive use is possible. The main benefit of the MCS, more than its specific elements (diagnostic or interactive), derives from the integration and complement of both in order to deal with dynamic tension (Hofmann et al., 2012). In this sense, mechanisms of control might be developed or adjusted according to the need to ensure a defined return (Ferreira \& Otley, 2009; Simons, 1995), requiring the structure of diagnostic and interactive control systems with the introduction of new mechanisms, key indicators, or details on current ones.

MCSs are used to exert control in attaining organizational goals and to enable employees to search for and expand on opportunities and to solve problems (Henri, 2006; Mundy, 2010). Some researchers have recognized that typical diagnostic tools can be used with MCSs as a means of interaction (Abernethy \& Brownell, 1999; Chenhall, 2003; Hofmann et al., 2012; Simons, 1995). As the interactive system can be considered the typical practice-based construct, it is characterized by the ways in which managers use it. Therefore, the way to look at and study an interactive control is not by using a single holistic construct, but rather a variety of meanings and methods (Bisbe, Batista-Foguet, \& Chenhall, 2006).

Hypothesis 8. Dynamic tensions positively affect innovation intensity.

Hypothesis 8 was not supported. A possible reason for dynamic tension existing is that it occurs in a complex loop. If the MCS captures something that must be addressed by executives, at some point it returns to the artifacts, such as strategic planning, budget, or forecast. As a result, the way to identify and understand this is by following the loop, which is not possible using the chosen model.

\section{Discussion and Conclusions}

The main aim of this paper is to examine the association between MCSs and the innovation process. This is relevant due to the innovation process de per si being a fundamental activity for 
organizational sustainability and due to the conflicting beliefs that MCSs can restrict the innovation process or incentivize it. Rather than examining this as a whole, the analysis focused on different elements of MCSs in order to capture behaviors that could together be offsite. The overall conclusion, providing a contribution to the latest research involving MCSs and innovation, is that MCSs, operationalized into diagnostic and interactive control systems, are associated with innovation, depending on antecedents comprised of distinct elements, such as external stimuli and innovation strategies. Another contribution is an improvement to the models that only consider internal variables, which is partly addressed with the inclusion of external stimuli. External stimuli are a very important issue in organizational life and must be part of a dynamic innovation process due to them being directly or indirectly associated with MCS elements. The static alternative, without recognizing issues of environment, in some situations destroys the potentiality of the models, something that recognizing external impacts mitigates risks.

However, there is a path traversed by these variables, and they are filtered in stages, beginning with external stimuli, passing through innovation strategies, and proceeding via the balance of dynamic tensions before reaching the interactive control system. Specifically referring to the two uses, diagnostic and interactive, is particularly relevant due to the controversial literature. In other words, although they are different, both are necessary and complementary, which is relevant and pragmatically important for the innovation process. Despite there are several studies on this, few are conclusive.

Another contribution refers to the controversy that was highlighted in this research involving the role of the diagnostic use of MCSs. Some of the literature considers that it restricts the innovation process or makes it complex and untimely in organizations, due to the financial format, the need for abundant information, and time demands etc. Another portion of the literature supports the idea that diagnostic use provides comfort for executives when monitoring innovation projects due to the need to control them in relation to planned performance. This research, despite statistically small effect, supported the second approach despite recognizing the criticism.

The study did not capture the impact of dynamic tension on radical innovation nor on incremental innovation, unlike what is expected by the dominant literature. It is possible that the model cannot capture this due to the complexity of the loop: dynamic tension is provoked by the diagnostic and interactive uses but, at some point, is addressed and used via the artifacts, requiring a loop, which is not considered in the model.

For an empirical study in an emergent country, the model was supported. It was accepted that emergent countries have some specific ways that management handles innovation. The management practices are defined according to needs or compliance with headquarters that make the perception of usefulness (Chong, 1996) a complex and very important issue in terms of management model acceptance and use.

In summary, the research contributes to analyzing the innovation process by using enhancing elements and treating them with a comprehensive model in order to impact the understanding and monitoring of innovation projects. Although no generalization is possible due to the design of the field research, the implications of this study are that the structure and maintenance of MCSs should be sensitive to the influences of the variables identified; otherwise, these systems would be detached from actual events and the needs of organizations. This perspective is important in various aspects of management, particularly in monitoring the innovation process.

The PLS estimation contains a bias (attenuation of the structural coefficients) that, in future studies, could be avoided in two ways: by collecting a bigger sample and using covariance based estimation with a robust method (we are afraid that this is extremely difficult in the current Brazilian context), or by increasing the number of indicators by means of latent variables (consistency at large) and running the model with SmartPLS. We tested the new PLS algorithm (PLSc or PLS-consistent) available in SmartPLS 3.2.3, but it improves the structural model results (the average increase of path coefficients equals 0.04), and jeopardizes the measurement model (convergent validity decreases). 
Another issue is the inclusion of controls in the structural model, which at the moment is not possible, because our sample is distributed among many sectors, and an artificial dichotomization to include this as a control variable does not improve the quality of the results and their interpretation.

As a suggestion for future research, a longitudinal study should analyze what types of innovation should be controlled by diagnostic control systems and how this control is developed. Additionally, more specific focus on dynamic tension is required, especially regarding the diagnostic use of MCSs and incremental innovation. On this point another contribution of this paper refers to the scale for measuring dynamic tension, which in prior studies was presented as a multiplication of diagnostic use by interactive use (Henri, 2006).

\section{Acknowledgments}

The first and second authors are CNPq PQ Scholarship - Brazil.

\section{References}

Abernathy, W. J., \& Utterback, J. M. (1978). Patterns of innovation in industry. Technology Review, 80(7), 40-47.

Abernethy, M. A., \& Brownell, P. (1999). The role of budgets in organizations facing strategic change: An exploratory study. Accounting, Organizations and Society, 24(3), 189-204. https://doi.org/10.1016/s0361-3682(98)00059-2

Adler, P. S., \& Chen, C. X. (2011). Combining creativity and control: Understanding individual motivation in large-scale collaborative creativity. Accounting, Organizations and Society, 36(2), 63-85. https://doi.org/10.1016/j.aos.2011.02.002.

Agbejule, A. (2011). Organizational culture and performance: The role of management accounting system. Journal of Applied Accounting Research, 12(1), 74-89. https://doi.org/10.1108/09675421111130621

Ahrens, T., \& Chapman, C. S. (2004). Accounting for flexibility and efficiency: A field study of management control systems in a restaurant chain. Contemporary Accounting Research, 21(2), 271-301. https://doi.org/10.1506/vjr6-rp75-7gux-xh0x

Anthony, R. N. (1976). Management accounting (4th ed.). Illinois: Irwin.

Anthony, R. N., \& Govindarajan, V. (2008). Sistemas de controle gerencial (12a ed.). São Paulo: McGraw- Hill.

Arjaliès, D.-L., \& Mundy, J. (2013). The use of management control systems to manage CSR strategy: A levers of control perspective. Management Accounting Research, 24(4), 284-300. https://doi.org/10.1016/j.mar.2013.06.003.

Arjaliès, D.-L., \& Péan, J.-M. (2009, September). CSR: A new business model for multinational companies? A study of the management systems used by the French CAC 40 companies to integrate CSR into their strategy. Proceedings of European Academy for Business in Society Conference (EABIS), Barcelona, Spain. 
Bedford, D. S. (2015). Management control systems across different modes of innovation: Implications for firm performance. Management Accounting Research, 28, 12-30. https://doi.org/10.1016/j.mar.2015.04.003

Bedford, D. S., \& Malmi, T. (2015). Configurations of control: An exploratory analysis. Management Accounting Research, 27, 2-26. https://doi.org/10.1016/j.mar.2015.04.002

Berry, A. J., Broadbent, J., \& Otley, D. (2005). Management control: Theories, issues and performance (2nd ed.). Basingstoke: Palgrave Macmillan.

Bisbe, J., Batista-Foguet, J., \& Chenhall, R. (2006). Defining management accounting: A methodological note on the risks of conceptual misspecification. Accounting, Organizations and Society, 32(7-8), 789-820. https//doi.org/10.1016/j.aos.2006.09.010

Bisbe, J., \& Malagueño, R. (2009). The choice of interactive control systems under different innovation management modes. European Accounting Review, 18(2), 371-405. https://doi.org/10.1080/09638180902863803

Bisbe, J., \& Otley, D. (2004). The effects of the interactive use of management control systems on product innovation. Accounting, Organizations and Society, 29(8), 709-737. http://doi.org/10.1016/j.aos.2003.10.010.

Carter, C., Clegg, S., \& Kornberger, M. (2010). Re-framing strategy: Power, politics and accounting. Accounting, Auditing \& Accountability Journal, 23(5), 573-594. https://doi.org/10.1108/09513571011054891

Chang, S.-J., Witteloostuijin, A., van, \& Eden, L. (2010). From the editors: Commom method variance in international business research. Journal of International Business Studies, 41(2), 178-184. https://doi.org/10.1057/jibs.2009.88

Chapman, C. S. (1997). Reflection on a contingency view of accounting. Accounting, Organizations and Society, 22(2), 189-205. https://doi.org/10.1016/S0361-3682(97)00001-9

Chenhall, R. H. (2003). Management control systems design within its organizational context: Findings from contingency-based research and directions for the future. Accounting, Organizations and Society, 28(2-3), 127-168. https://doi.org/10.1016/S0361-3682(01)00027-7

Chenhall, R. H. (2007). Theorizing contingencies in management control systems research. In C. S. Chapman, A. G. Hopwood, \& M. D. Shields (Eds.), Handbook of management accounting research (pp. 163-206). Oxford: Elsevier.

Chenhall, R. H., \& Morris, D. (1995). Organic decision and communication processes and management accounting systems in entrepreneurial and conservative business organizations. Omega, 23(5), 485-497. https://doi.org/10.1016/0305-0483(95)00033-K

Chong, V. K. (1996). Management accounting systems, task, uncertainty and managerial performance: A research note. Accounting, Organizations and Society, 21(5), 415-421. https://doi.org/10.1016/0361-3682(95)00045-3

Cliff, J. E., \& Jennings, P. D. (2005). Commentary on the multidimensional degree of family influence construct and the F-PEC measurement instrument. Entrepreneurship Theory and Practice, 29(3), 341-347. https://doi.org/10.1111/j.1540-6520.2005.00087.x

Coad, A. F., \& Herbert, I. P. (2009). Back to the future: New potential for structuration theory in management accounting research? Management Accounting Research, 20(3), 177-192. https://doi.org/10.1016/j.mar.2009.02.001 
Cohen, J. (1988). Statistical power analysis for the behavioral sciences (2nd ed.). New York: Psychology Press.

Cohen, J., Cohen, P., West, S. G., \& Aiken, L. S. (2003). Applied multiple regression/correlation analysis for the behavioral sciences (3rd ed.). New Jersey: Lawrence Erlbaum Associates, Publishers.

Coviello, N. E., \& Jones, M. V. (2004). Methodological issues and international entrepreneurship research. Journal of Business Venturing, 19(4), 485-508. https://doi.org/10.1016/j.jbusvent.2003.06.001

Cruz, A. P. C., Frezatti, F., \& Bido, D. de S. (2015). Estilo de liderança, controle gerencial e inovação: Papel das alavancas de controle. Revista de Administração Contemporânea, 19(6), 772-794. Retrieved from http://www.scielo.br/pdf/rac/v19n6/1982-7849-rac-19-6-0772.pdf. https://dx.doi.org/10.1590/1982-7849rac2015150099

Daft, R. I., \& Macintosh, N. B. (1978). A new approach to design and use of management information. California Management Review, 21(1), 82-92. https://doi.org/10.2307/41165297

Damanpour, F. (1991). Organizational innovation: A meta-analysis of effects of determinants and moderators. Academy of Management Journal, 34(3), 555-590. https://doi.org/10.2307/256406

Damanpour, F., \& Evan, W. M. (1984). Organizational innovation and performance: The problem of organizational lag. Administrative Science Quarterly, 29(3), 392-409. https://doi.org/10.2307/2393031

Damanpour, F., \& Gopalakrishnan, S. (1998). Theories of organizational structure and innovation adoption: The role of environmental change. Journal of Engineering and Technology Management, 15(1), 1-24. https://doi.org/10.1016/S0923-4748(97)00029-5

Davila, T. (2005). The promise of management control systems for innovation and strategic change. In C. S. Chapman (Ed.), Controlling strategy: Management, accounting, and performance measurement (pp. 37-61). New York: Oxford University Press.

Davila, T., \& Wouters, M. (2005). Managing budget emphasis through the explicit design of conditional budgetary slack. Accounting, Organizations and Society, 30(7-8), 587-608. https://doi.org/10.1016/j.aos.2004.07.002

Devellis, R. F. (2003). Scale development: Theory and applications (2nd ed.). Thousand Oaks: Sage Publications.

Etherington, L., \& Tjosvold, D. (1998). Managing budget conflicts: contribution of goal interdependence and interaction. Canadian Journal of Administrative Sciences / Revue Canadienne des Sciences de l'Administration, 15(2), 142-151. https://doi.org/10.1111/j.19364490.1998.tb00158.x

Ettlie, J. E., Bridges, W. P., \& O’ Keefe, R. D. O. (1984). Organization strategy and structural differences for radical versus incremental innovation. Management Science, 30(6), 682-695. https://doi.org/10.1287/mnsc.30.6.682

Ferreira, A., \& Otley, D. (2009). The design and use of performance management systems: An extended framework for analysis. Management Accounting Research, 20(4), 263-282. https://doi.org/10.1016/j.mar.2009.07.003

Freeman, C. (1995). The 'national system of innovation' in historical perspective. Cambridge Journal of Economics, 19(1), 5-24. https://doi.org/10.1093/oxfordjournals.cje.a035309 
Germain, R. (1996). The role of context and structure in radical and incremental logistics innovation adoption. Journal of Business Research, 35(2), 117-127. https://doi.org/10.1016/01482963(95)00053-4

Gersick, C. J. G. (1991). Revolutionary change theories: A multilevel exploration of the punctuated equilibrium paradigm. The Academy of Management Review, 16(1), 10-36. https://doi.org/10.2307/258605

Gopalakrishnan, S., \& Damanpour, F. (1994). Patterns of generation and adoption of innovation in organizations: Contingency models of innovation attributes. Journal of Engineering and Technology Management, 11(2), 95-116. https://doi.org/10.1016/0923-4748(94)90001-9

Groot, T., \& Lukka, K. (2000). Cases in management accounting. Harlow: Prentice Hall.

Gupta, A. K., \& Govindarajan, V. (2001). Converting global presence into global competitive advantage. Academy of Management Executive, 15(2), 45-58. https://doi.org/10.5465/ame.2001.4614881

Gupta, V., Levernburg, N. M., Moore, L., Motwani, J., \& Schwarz, T. V. (2011). The spirit of family business: A comparative analysis of Anglo, Germanic and Nordic nations. International Journal of Cross Cultural Management, 11(2), 133-151. https://doi.org/10.1177/1470595811399187

Hair, J. F., Jr., Black, W. C., Babin, B. J., \& Anderson, R. E. (2010). Multivariate data analysis. Upper Side River: Prentice Hall.

Hair, J. F., Jr., Hult, G. T. M., Ringle, C. M., \& Sarstedt, M. (2014). A primer on partial least squares structural equation modeling (PLS-SEM). Thousand Oaks, CA: Sage Publications, Inc.

Haustein, E., Luther, R., \& Schuster, P. (2014). Management control systems in innovation companies: A literature based framework. Journal of Management Control, 24(4), 343-382. https://doi.org/10.1007/s00187-014-0187-5.

Henri, J. (2006). Management control systems and strategy: A resource-based perspective. Society, 31(6), 529-558. http://doi.org/10.1016/j.aos.2005.07.001

Henseler, J., Ringle, C. M., \& Sinkovics, R. R. (2009). The use of partial least squares path modeling in international marketing. In R. R. Sinkovics \& P. N. Ghauri (Eds.), New challenges to international marketing (Advances in International Marketing, Vol. 20, pp. 277-319). Bingley, UK: Emerald Group Publishing Limited.

Hoffmann, S., Mai, R., \& Smirnova, M. (2011). Development and validation of a cross-nationally stable scale of consumer animosity. The Journal of Marketing Theory and Practice, 19(2), 235-252. http://doi.org/10.2753/MTP1069-6679190208

Hofmann, S., Wald, A., \& Gleich, R. (2012). Determinants and effects of the diagnostic and interactive use of control systems: An empirical analysis on the use of budgets. Journal of Management Control, 23(3), 153-182. http://doi.org/10.1007/s00187-012-0156-9

Holt, D. T., Rutherford, M. W., \& Kuratko, D. F. (2010). Advancing the field of family business research: Further testing the measurement properties of the F-PEC. Family Business Review, 23(1), 76-88. https://doi.org/10.1177/0894486509349943

Hoskisson, R. E., Eden, L., Lau, C. M., \& Wright, M. (2000). Strategy in emerging economies. Academy of Management Journal, 43(3), 249-267. Retrieved from http://www.jstor.org/stable/1556394

Hunt, S. D., \& Duhan, D. F. (2002). Competition in the third millennium: Efficiency or effectiveness? Journal of Business Research, 55(2), 97-102. https://doi.org/10.1016/s0148-2963(00)00144-2 
Jack, L., \& Mundu, J. (2013). Routine and change: The role of management accounting and control. Journal of Accounting \& Organizational Change, 9(2), 112-118. https://doi.org/10.1108/18325911311325924

Jarzabkowski, P. (2004). Strategy as practice: Recursiveness, adaptation, and practices-in-use. Organization Studies, 25(4), 529-560. https://doi.org/10.1177/0170840604040675

Kaplan, R. S., \& Norton, D. P. (1996). Balanced scorecard: Translating strategy into action. Boston: Harvard Business School Press.

Koberg, C. S., Detienne, D. R., \& Heppard, K. A. (2003). An empirical test of environmental, organizational, and process factors affecting incremental and radical innovation. The Journal of High Technology Management Research, 14(1), 21-45. https://doi.org/10.1016/s10478310(03)00003-8

Kober, R., Ng, J., \& Paul, B. J. (2007). The interrelationship between management control mechanisms and strategy. Management Accounting Research, 18(4), 425-452. https://doi.org/10.1016/j.mar.2007.01.002

Little, T. D., Lindenberger, U., \& Nesselroade, J. R. (1999). On selecting indicators for multivariate measurement and modeling with latent variables: When "good" indicators are bad and "bad" indicators are good. Psychological Methods, 4(2), 192-211. https://doi.org/10.1037//1082989x.4.2.192

Malagueño, R., \& Bisbe, J. (2010). The role of management accounting and control systems as antecedents of organizational creativity and innovation capabilities. Retrieved from http://papers.ssrn.com/sol3/papers.cfm?abstract_id=1720989

Malmi, T., \& Brown, D. (2008). Management control systems as a package - opportunities, challenges and research directions. Management Accounting Research, 19(4), 287-300. https://doi.org/10.1016/j.mar.2008.09.003

Meyer, K. E., Estrin, S., Bhaumik, S. K., \& Peng, M. W. (2009). Institutions, resources and entry strategies in emerging economies. Strategic Management Journal, 30(1), 61-80. https://doi.org/10.1002/smj.720

Moll, J. (2015). Editorial: Special issue on innovation and product development. Management Accounting Research, 28, 2-11. https://doi.org/10.1016/j.mar.2015.05.003

Mundy, J. (2010). Creating dynamic tensions through a balanced use of management control systems. Accounting, Organizations and Society, 35(5), 499-523. https://doi.org/10.1016/j.aos.2009.10.005

Naranjo-Gil, D., \& Hartmann, F. (2007). Management accounting systems, top management team heterogeneity and strategic change. Accounting, Organizations and Society, 32(7/8), 735-756. https://doi.org/10.1016/j.aos.2006.08.003

Podsakoff, P. M., MacKenzie, S. B., Lee, J.-Y., \& Podsakoff, N. P. (2003). Common method biases in behavioral research: A critical review of the literature and recommended remedies. The Journal of Applied Psychology, 88(5), 879-903. https://doi.org/10.1037/0021-9010.88.5.879

Porter, M. (1989). Vantagem competitiva. Rio de Janeiro: Campus.

Ringle, C. M., Sarstedt, M., \& Straub, D. W. (2012). A critical look at the use of PLS-PM in MIS Quarterly. MIS Quarterly, 36(1), iii-xiv. Retrieved from http://misq.org/skin/frontend/default/misq/pdf/V36I1/EdCommentsV36N1.pdf

Rogers, E. M. (1995). Diffusion of innovations. New York: The Free Press. 
Schumpeter, J. A. (1997). Teoria do desenvolvimento econômico: uma investigação sobre lucros, capital, crédito, juro e ciclo econômico. São Paulo: Nova Cultural.

Simons, R. (1991). Strategic orientation and top management attention to control systems. Strategic Management Journal, 12(1), 49-62. https://doi.org/10.1002/smj.4250120105

Simons, R. (1994). How new top managers use control systems as levers of strategic renewal. Strategic Management Journal, 15(3), 169-189. https://doi.org/10.1002/smj.4250150301

Simons, R. (1995). Levers of control: How managers use innovative control systems to drive strategic renewal. Boston: Harvard Business Press.

Sitkin, S. B. (1996). Learning through failure: The strategy of small losses. In M. D. Cohen \& L. S. Sproull (Eds.), Organizational learning (pp. 541-578). Thousand Oaks: Sage Publications.

Su, S., Baird, K., \& Schoch, H. (2015). The moderating effect of organisational life cycle stages on the association between the interactive and diagnostic approaches to using controls with organisational performance. Management Accounting Research, 26, 40-53. https://doi.org/10.1016/j.mar.2014.09.001

Sutton, C. (1998). Strategic concepts. Basingstoke: Macmillan Publishers.

Teece, D. J. (2010). Business models, business strategy and innovation. Long Range Planning, 43(2/3), 172-194. https://doi.org/10.1016/j.lrp.2009.07.003

Tessier, S., \& Otley, D. (2012). From management controls to the management of controls. Accounting, Auditing \& Accountability Journal, 25(5), 776-805. https://doi.org/10.1108/09513571211234259

Tushman, M., \& Romanelli, E. (1985). Organizational evolution: A metamorphosis model of convergence and reorientation. Research in Organizational Behavior, 7, 171-222.

Un, C. A., Cuervo-Cazurra, A., \& Asakawa, K. (2010). R\&D collaborations and product innovation. The Journal of Product Innovation Management, 27(3), 673-689. https://doi.org/10.1111/j.15405885.2010.00744.x

Widener, S. K. (2007). An empirical analysis of the levers of control framework. Accounting, Organizations and Society, 32(7/8), 757-788. http://doi.org/10.1016/j.aos.2007.01.001

Zimmerman, J. (2011). Accounting for decision making and control. New York: McGraw-Hill.

\title{
Authors' Profiles
}

\author{
Fábio Frezatti \\ Av. Prof. Luciano Gualberto, 908, Cidade Universitária, FEA 3, 05508-010, São Paulo, SP, Brazil. E-mail address: \\ frezatti@usp.br \\ Diógenes de Souza Bido \\ Rua da Consolação, 930, 01302-907, São Paulo, SP, Brazil. E-mail address: diogenesbido@ yahoo.com.br \\ Ana Paula Capuano da Cruz \\ Av. Itália, km 8, s/nº, 96201-900, Rio Grande, RS, Brazil. E-mail address: anapaulacapuanocruz@ hotmail.com \\ Maria José C. Machado \\ SP 308, km 156, Piracicaba, SP, Brazil. E-mail address: mjczen@ gmail.com
}




\section{APPENDIX}

\section{Questionnaire}

\begin{tabular}{l|l|l|l|} 
S & M & SD & FL \\
\hline
\end{tabular}

\begin{tabular}{|c|c|c|c|c|c|}
\hline \multirow{6}{*}{ 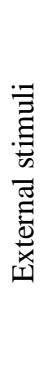 } & \multicolumn{5}{|c|}{$\begin{array}{l}\text { Answer the questions below according to your level of agreement. As a general rule, in your organization, } \\
\text { external stimuli for INNOVATION come from: }\end{array}$} \\
\hline & Q251 dynamics of international competition & (a) & 3.4 & 1.56 & 0.64 \\
\hline & Q252 governmental regulation and deregulation & (a) & 3.9 & 1.13 & $\mathrm{X}$ \\
\hline & Q253 increases in customer demands & (a) & 4.5 & 0.87 & 0.79 \\
\hline & Q254 restrictions on the availability of scarce resources & (a) & 3.7 & 1.22 & $\mathrm{X}$ \\
\hline & Q255 competitor advances that threaten current and future products & (a) & 4.0 & 1.19 & 0.74 \\
\hline
\end{tabular}

\begin{tabular}{|c|c|c|c|c|c|}
\hline \multirow{7}{*}{ 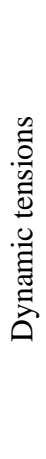 } & \multicolumn{5}{|c|}{$\begin{array}{l}\text { Dynamic tension in a company is something that creates a conflict in its management. Indicate your level of } \\
\text { agreement with the specified types of dynamic tension more relevant to innovation opportunities: }\end{array}$} \\
\hline & Q511 unlimited opportunities (worth any innovation opportunity) & (a) & 3.2 & 1.15 & $\mathrm{X}$ \\
\hline & $\begin{array}{l}\text { Q512 limited attention (the focus is clearly defined as is the time used to make } \\
\text { the focus viable) }\end{array}$ & (a) & 3.7 & 1.02 & 0.62 \\
\hline & Q521 current strategies (previously decided in the formal planning process) & (a) & 4.0 & 0.96 & 0.83 \\
\hline & Q522 emerging (not yet observed in the formal planning process) & (a) & 3.7 & 0.94 & 0.68 \\
\hline & Q531 manager self-interest & (a) & 3.6 & 1.18 & $\mathrm{X}$ \\
\hline & Q532 desire to contribute to the organization & (a) & 4.2 & 0.76 & 0.69 \\
\hline
\end{tabular}

\begin{tabular}{|c|c|c|c|c|c|}
\hline \multirow{6}{*}{ 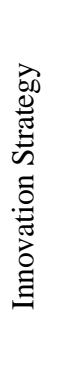 } & \multicolumn{5}{|c|}{$\begin{array}{l}\text { Answer the questions below according to your level of agreement. As a general rule, in your organization } \\
\text { INNOVATION encompasses changes (in business dimensions): }\end{array}$} \\
\hline & Q221 in processes & (a) & 4.4 & 0.75 & 0.72 \\
\hline & Q222 in technologies & (a) & 4.5 & 0.74 & 0.67 \\
\hline & Q223 in products & (a) & 4.3 & 1.06 & 0.52 \\
\hline & Q224 in the organisation & (a) & 3.9 & 1.21 & 0.64 \\
\hline & Q225 in the manner in which products and services are marketed/offered & (a) & 4.0 & 1.08 & 0.84 \\
\hline
\end{tabular}

\begin{tabular}{|l|lllll|}
\hline & $\begin{array}{l}\text { Answer the questions below according to your level of agreement. } \\
\text { Q111. there is formalized strategic planning in the company }\end{array}$ & (b) & 3.2 & 0.97 & 0.80 \\
& Q112. the company has an annual budget & (b) & 3.7 & 0.74 & 0.65 \\
& Q113. the budget is aligned with and derives from strategic planning & (b) & 3.1 & 1.05 & 0.88 \\
& $\begin{array}{l}\text { Q114. there is a rolling forecast (projections aimed at providing financial } \\
\text { results) }\end{array}$ & (b) & 3.2 & 1.13 & 0.64 \\
Q115. there is a capital budget (plan of investment projects) & (b) & 3.4 & 0.99 & 0.76 \\
Q116. the company has budgetary control & (b) & 3.7 & 0.52 & 0.69 \\
Q117. individual performance explained by budgetary control affects the & (b) & 2.5 & 1.39 & 0.58 \\
\hline
\end{tabular}




\begin{tabular}{|c|c|c|c|c|c|}
\hline \multirow{6}{*}{ 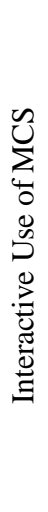 } & \multicolumn{5}{|c|}{$\begin{array}{l}\text { To what extent do you agree that the organization has the characteristics described below for identifying projects } \\
\text { and actions that involve INNOVATION? }\end{array}$} \\
\hline & $\begin{array}{l}\text { Q411. information on innovation is an important element for the highest level } \\
\text { of managers }\end{array}$ & (b) & 4.0 & 1.20 & 0.76 \\
\hline & $\begin{array}{l}\text { Q412. regular and frequent attention is devoted to the analysis and discussion } \\
\text { of innovation by managers at all levels }\end{array}$ & (b) & 3.6 & 1.26 & 0.83 \\
\hline & $\begin{array}{l}\text { Q413. data generated by the system are interpreted and discussed in meetings } \\
\text { with superiors, subordinates and peers }\end{array}$ & (b) & 3.7 & 1.24 & 0.85 \\
\hline & $\begin{array}{l}\text { Q414. the system is a way to catalyse the ongoing challenge and subsequent } \\
\text { debates about information, expectations and plans }\end{array}$ & (b) & 3.5 & 1.37 & 0.81 \\
\hline & Q415. the innovation project is monitored after implementation & (b) & 3.8 & 1.38 & 0.71 \\
\hline
\end{tabular}

\begin{tabular}{|c|c|c|c|c|}
\hline \multirow{3}{*}{ 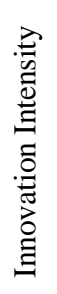 } & \multicolumn{4}{|c|}{$\begin{array}{l}\text { When talking about INNOVATION in your organization, in terms of emphasis on project development, which } \\
\text { of the following types of innovation occur: }\end{array}$} \\
\hline & $\begin{array}{l}\text { Q211. incremental: changes (continuous or not) to improve what already } \\
\text { exists. Example: an improved product, an improved process, etc. }\end{array}$ & 4.6 & 0.78 & 1 \\
\hline & $\begin{array}{l}\text { Q213. radical: revolutionary changes. Example: a product outside the } \\
\text { previous focus of the company, a completely different production process for } \\
\text { the business, etc. }\end{array}$ & 3.2 & 1.61 & 1 \\
\hline
\end{tabular}

Note. 1: All factor loadings are significant $(\mathrm{p}<0.001)$. 2: Incremental and radical innovation were measured as single item, for this reason the loadings are equal 1.0. $\mathbf{X}=$ Indicators removed from the measurement model because of presenting low factor loading. $\mathbf{S}=$ scale $\mathbf{M}=$ mean; $\mathbf{S D}=$ standard deviation; $\mathbf{F L}=$ factor loading.

Legend: (a) 5 (strongly agree), 4 (partially agree), 3 (neither agree nor disagree), 2 (partially disagree), 1 (strongly disagree), 0 (do not know). / (b) 4 (exists and is used to measure and monitor the effect of innovation), 3 (exists and is used in a general way, not to monitor innovation), 2 (exists but is not really used by management), 1 (does not exist in the organization), 0 (do not know). 